\section{Angela Kuck}

In der Behandlung der vaginalen Infektionen nimmt die lokale Anwendung der ätherischen Öle eine Domäne [1] neben der systemischen Stärkung des Immunsystems ein.

Die beginnende Soorkolpitis mit noch leichter Symptomatik kann gut mit pflanzlichen Präparaten aus einer Kombination von ätherischen Ölen behandelt werden. Häufig verwendet werden Majorana comp. Gel und Argentum/Quercus Vaginaltabletten. Da eine pflanzlich oder chemisch behandelte Soorkolpitis in der Schwangerschaft oft rezidiviert, hat sich eine Rezidivprophylaxe mit lokalen ätherischen Ölen bewährt. Hier haben wir Lavendelöl (Abb. 1) und Teebaumöl (Abb. 2) für die vaginale Applikation verdünnt und zudem mit Rosenöl gute Erfahrungen gesammelt (Tab. 1).

Eine ausgeprägte, lange bestehende Soorkolpitis mit ausgedehnten Belägen und intramukös ausgebreiteten Myzelien spricht seltener auf eine pflanzliche Behandlung an. Die Ansäuerung des Vaginalmilieus sowie die Stärkung der Döderlein-Flora haben sich inzwischen allgemein durchgesetzt.
*Nach einem Beitrag zur 3. Jahrestagung der Schweizerischen Arbeitsgemeinschaft für Perinatale Pharmakologie (SAPP) vom 9.12.2010.

\title{
Komplementärmedizinische Therapieansätze zur Behandlung von Soor, bakterieller Vaginose und Clamydien in der Schwangerschaft*
}

Eine bakterielle Vaginose fällt nicht immer durch Symptome wie z.B. den fischartig riechenden Fluor auf. Häufig ist der Fluor bei der vaginalen Einstellung pathologisch vermehrt, der $\mathrm{pH}$-Wert ist in den alkalischen Bereich verschoben, und das Nativpräparat mit den typischen Clue Cells oder die Kultur sind diagnoseweisend. Aufgrund des Zusammenhangs mit der Frühgeburtlichkeit wird heute eine Behandlung $a b$ der Frühschwangerschaft empfohlen. Die antibiotische Behandlung hat nicht die gewünschte Senkung der Frühgeburtenrate bewirken können; die Rezidive sind häufiger. Hier hat sich besonders die lokale Anwendung von Majorana comp. Gel bewährt. Eine Anwendungsbeobachtung mit $102 \mathrm{~Pa}-$

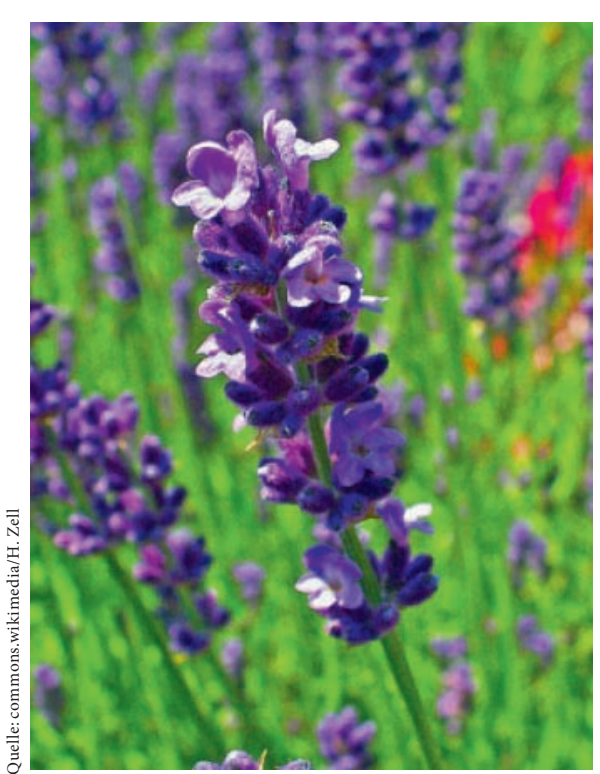

Abb. 1. Lavandula angustifolia (Lavendel). tientinnen bestätigt dies. Eine weitere Option sind Majorana/Melissae Vaginaltabletten (D) (Tab. 1); damit können in der Schwangerschaft mehr als die Hälfte der Gardnerellen-Infektionen erfolgreich behandelt werden. Nach antibiotischer Behandlung ist es hilfreich in der Rezidivprophylaxe.

Bei bestehendem Vitamin-D-Mangel ist die Gardnerella-Infektion häufiger, wie kürzlich im American Journal of Obstetrics and Gynecology [2] publiziert wurde. Deshalb sollten wir auch den Vitamin-D-Mangel ausgleichen.

In der Behandlung einer nachgewiesenen Clamydieninfektion erfolgt die antibiotische Therapie an erster Stelle. Bei der Behandlung der Nebenwirkungen und der nach

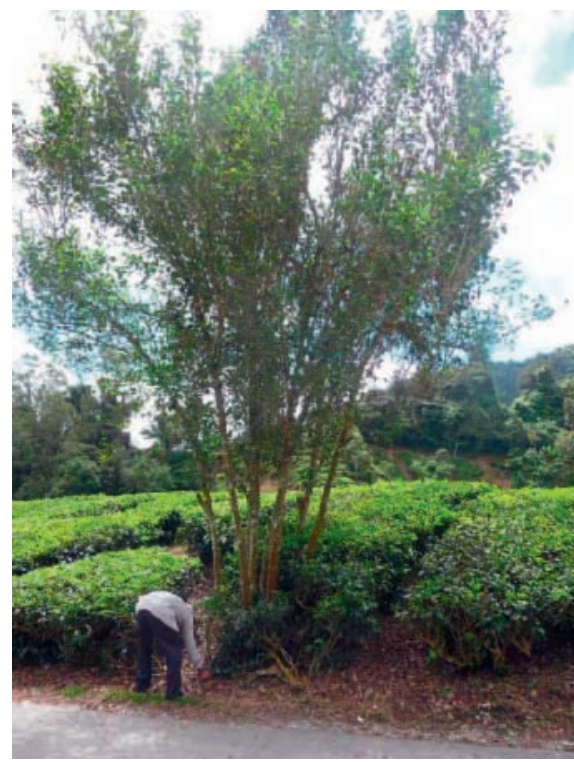

Abb. 2. Melaleuca alternifolia (Teebaum).

\section{KARGER}

Fax +497614520714 Information@Karger.d www.karger.com
(๑) 2011 S. Karger GmbH, Freiburg

Accessible online at: www.karger.com/szg
Dr. med. Angela Kuck

Chefärztin Gynäkologie und Geburtshilfe

Paracelsus-Spital Richterswil

Bergstrasse 16, 8005 Richterswil, Schweiz

Tel. +41 447872450

Angela.kuck@paracelsus-spital.ch 
Antibiose folgenden Soorkolpitis kommen die komplementären Therapien, wie oben beschrieben, zum Einsatz.
Die systemische Mitbehandlung des Immunsystems in der Schwangerschaft kann mit Echinacea, Prunus spinosa, Lichtaufnahme und Kombi-

\section{Literatur}

1 Reichling J, Schnitzler P, Suschke U, Saller R: Essential oils of aromatic plants with antibacterial, antifungal, antiviral, and cytotoxic

nationsmedikamenten erfolgen. Es haben sich dabei Ferrum sidereum/ Phosphor/Quarz (CH) Globuli, Ferrum/Quarz/Prunus Dil oder Solum uliginosum comp. Globuli als zweiter Pfeiler der Behandlungsoptionen bewährt. properties - an overview. Forsch Komplementmed 2009;16:79-90.

Hensel KJ, Randis TM, Gelber SE, Ratner AJ: Pregnancy-specific association of vitamin D deficiency and bacterial vaginosis. Am J Obstet Gynecol 2011;204:41.e1-9. 